\title{
Increased Women's Cardiovascular Mortality in their forties after Hypertensive Disorders of Pregnancy: A national cohort study
}

\author{
Sophie Welters ${ }^{1}$, Pim Teunissen ${ }^{1}$, Anita Ravelli ${ }^{2}$, Wietske Hermes ${ }^{3}$, and Christianne de \\ Groot $^{1}$
}

\author{
${ }^{1}$ Amsterdam UMC \\ ${ }^{2}$ Amsterdam UMC - Locatie AMC \\ ${ }^{3}$ Medisch Centrum Haaglanden Westeinde
}

June 29, 2020

\begin{abstract}
Objective: To determine the association between HDP and cardiovascular mortality. Design: Cohort study Setting: Population based using the Dutch National Birth Hospital Registry linked with the National Death Registry. Population: All women who gave birth between 1995 - 2015 Methods: Cox-regression models with hazard ratios (HR) and survival curves were executed. Main outcome and measures: The cardiovascular mortality risk after HDP was analyzed. Cardiovascular mortality-risk was analyzed in women with a history of HDP in one or more pregnancies compared to women without a history of HDP. In a subgroup of this cohort the effect of HDP on cardiovascular mortality was analyzed using only the nulliparous pregnancy of women. Results: Women were followed for a mean time of 10.4 years. Of 1,625,246 parous women $21.9 \%$ had a history of HDP. Gestational hypertension (18.1\%) was associated with an aHR of 2.13 (95\% CI: 1.91 - 2.38) for CVM. Preeclampsia (3.8\%) was associated with an aHR of 3.35 (95 \% CI: 2.80 - 4.00) for CVM. Cardiovascular mortality risk was highest in women with a history of HDP combined with a preterm birth ( $<37$ weeks) and a growth restricted child (
\end{abstract}

\section{Hosted file}

BJOG - Manuscript.pdf available at https://authorea.com/users/337644/articles/463275increased-women-s-cardiovascular-mortality-in-their-forties-after-hypertensivedisorders-of-pregnancy-a-national-cohort-study

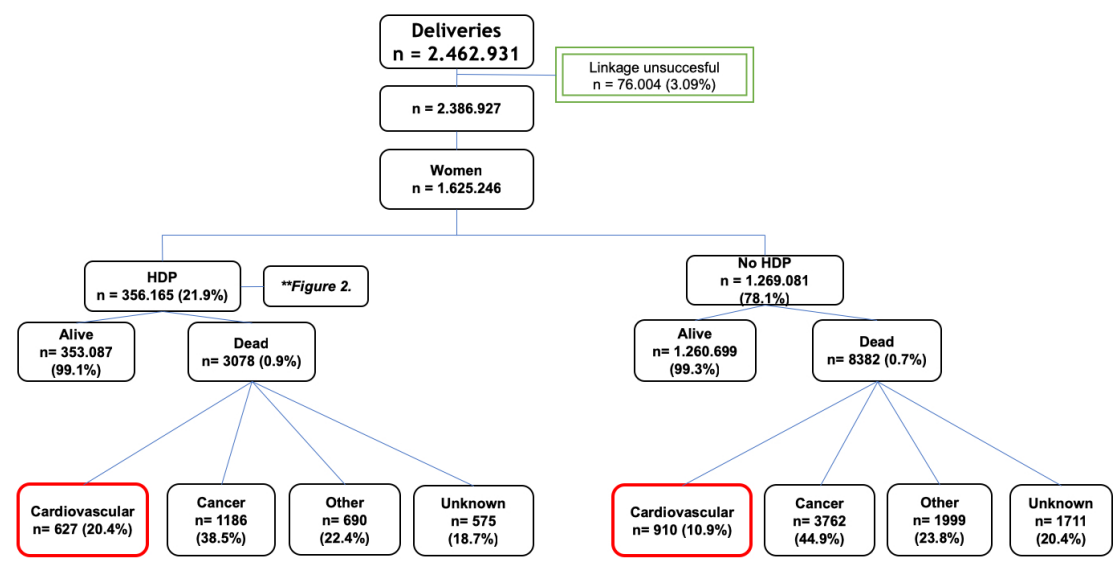




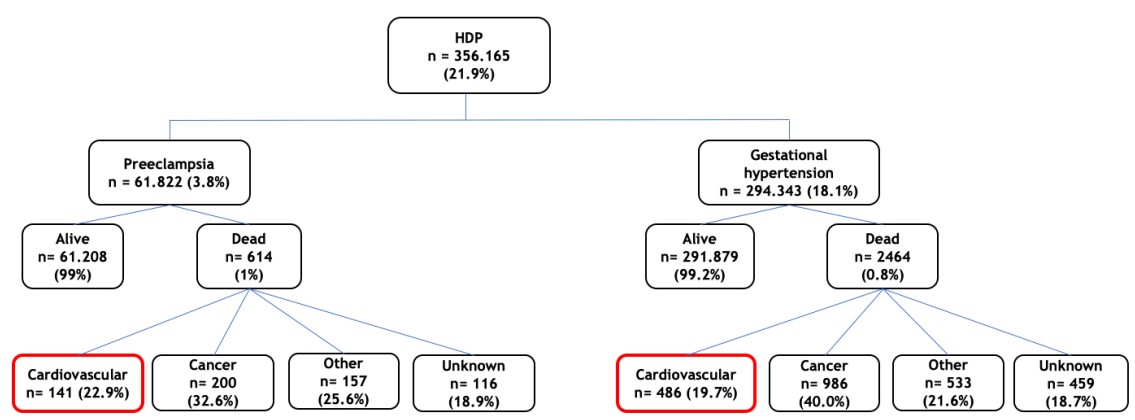

\section{Hosted file}

Table 1a.docx available at https://authorea.com/users/337644/articles/463275-increased-womens-cardiovascular-mortality-in-their-forties-after-hypertensive-disorders-of-pregnancy-anational-cohort-study

\section{Hosted file}

Table 2a.docx available at https://authorea.com/users/337644/articles/463275-increased-womens-cardiovascular-mortality-in-their-forties-after-hypertensive-disorders-of-pregnancy-anational-cohort-study

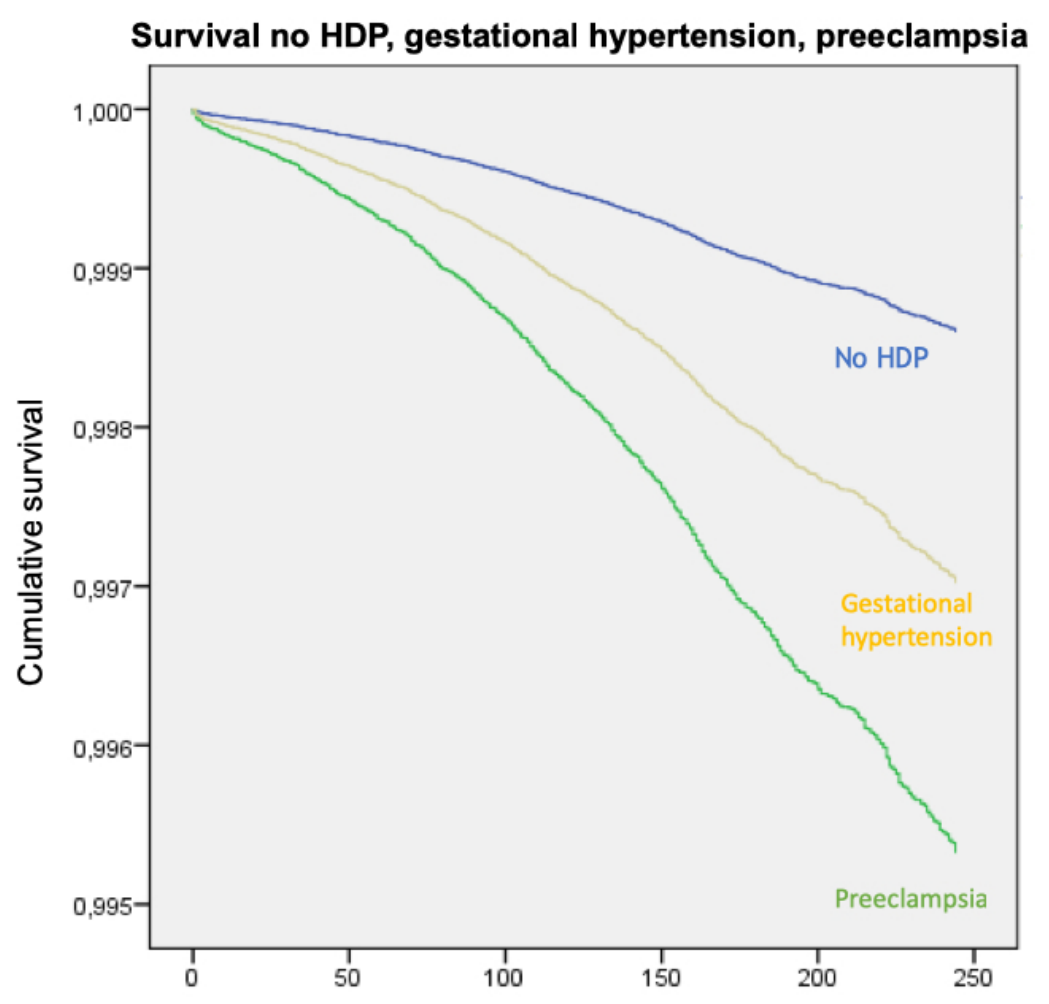

Follow-up in months from last delivery till death or end of follow-up 


\section{Hosted file}

Table 1b.docx available at https://authorea.com/users/337644/articles/463275-increased-womens-cardiovascular-mortality-in-their-forties-after-hypertensive-disorders-of-pregnancy-anational-cohort-study

\section{Hosted file}

Table 2b.docx available at https://authorea.com/users/337644/articles/463275-increased-womens-cardiovascular-mortality-in-their-forties-after-hypertensive-disorders-of-pregnancy-anational-cohort-study

Survival no HDP, gestational hypertension, preeclampsia

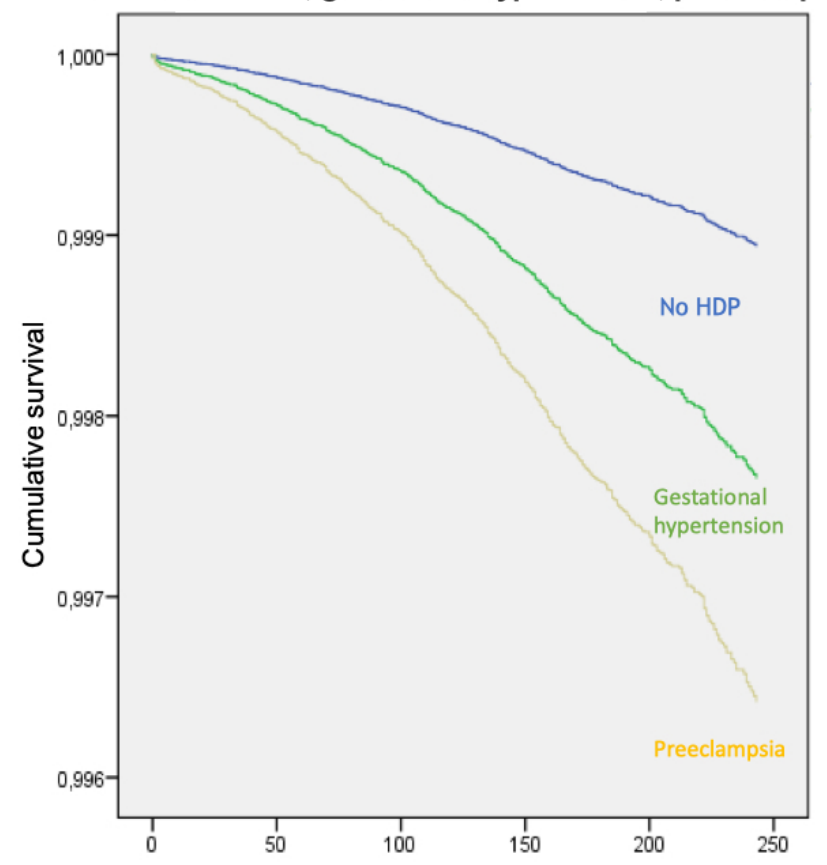

Follow-up in months from first delivery till death or end of follow-up 